\section{US space agency sharpens focus on near-Earth objects}

[WASHINGTON] The US space agency NASA plans to double its budget for studying nearEarth objects this year, following a meeting last month to assess the progress of current asteroid searches (see Nature 392, 215; 1998).

The increase to $\$ 3$ million affects only the 1998 budget, says NASA's Solar System exploration chief, Carl Pilcher. Future spending is yet to be determined. The agency will also set up a new office to coordinate research on near-Earth objects.

NASA underwrites the lion's share of such research in the United States, with additional funding coming from the air force. But past spending levels - between $\$ 1$ million and $\$ 1.5$ million a year - are insufficient to achieve the long-held goal of identifying most large, threatening asteroids within a decade. An estimated 90 per cent of such objects have yet to be detected.

The new NASA office will decide how to augment several searches for near-Earth objects already under way or planned. It will also decide policy for informing the public about future asteroid threats, which many scientists believe was bungled last month. Under a draft policy proposed last week, NASA-funded researchers would have to notify the agency and consult other asteroid scientists before issuing public statements.

Data on near-Earth objects received at the Minor Planet Center (MPC) at the HarvardSmithsonian Center for Astrophysics in Cambridge, Massachusetts, would be released to scientists "generally within 24 hours of receipt". Asteroid scientists have accused the MPC of not sharing data promptly.

Some non-US asteroid researchers are uneasy about a US government agency dictating who should talk to whom when an Earth-threatening object is discovered. The MPC, they say, operates under the auspices of the International Astronomical Union (IAU), and should remain independent.

But IAU's assistant general secretary, Hans Rickman of the Uppsala Astronomical Observatory in Sweden, sees no problem, as long as NASA policy is not presumed to apply to all asteroid researchers worldwide. He says NASA "has every right to require certain things" of the researchers it funds. The IAU should formulate its own policy on asteroid warnings and data sharing, he says.

Rickman agrees that dissemination of data by the MPC "could be done more efficiently". But he points out that the centre, which serves the entire international astronomical community, currently operates under severe financial and staffing constraints.

Tony Reichhardt

\title{
Petition strengthens hand of global warming sceptics
} signed a petition that rejects the Kyoto agreement on global warming and argues that increases in carbon dioxide levels benefit Earth, according to the petition's organizers.

The petition is likely to be released by the George Marshall Institute in Washington DC in the near future, and opponents of the Kyoto agreement are expected to use it to back up their arguments about a lack of scientific consensus on the issue.

But the mass-mailing of the petition to scientists - accompanied by a lengthy review article that had not been peer-reviewed or published - has angered some of those who believe that carbon dioxide emissions are a serious problem. They also argue that the number of signatories is a relatively small proportion of those who were mailed.

"Virtually every scientist in every field got it," says Robert Park, a professor of physics at the University of Maryland at College Park and spokesman for the American Physical Society. "That's a big mailing." According to the National Science Foundation, there are more than half a million science or engineering PhDs in the United States, and ten million individuals with first degrees in science or engineering.

Arthur Robinson, president of the Oregon Institute of Science and Medicine, the small, privately funded institute that circulated the petition, declines to say how many copies were sent out. "We're not willing to
[WASHINGTON] About 15,000 US science graduates, including 6,000 PhDs, have

have our opponents attack us with that number, and say that the rest of the recipients are against us," he says, adding that the response was "outstanding" for a direct mail shot.

The Union of Concerned Scientists has branded the exercise as "a deliberate attempt to deceive the scientific community with misinformation on the subject of climate change". And prominent members of the National Academy of Sciences, whose pastpresident, Frederick Seitz, wrote a cover letter for the mailing, are also upset, according to a spokesperson for the academy, partly because the article in the mailinglooks exactly like a paper from the Proceedings of the National Academy of Sciences (PNAS).

Robinson, a biochemist and former close associate of Linus Pauling, co-authored the article with Sallie Baliunas, a planetary scientist at Harvard University and noted global warming sceptic, and with Robinson's son Zachary, who has just obtained his bachelor's degree from Oregon State University. The article, "Environmental effects of increased atmospheric carbon dioxide", argues that the release of more carbon dioxide "will help to maintain and improve the health, longevity, prosperity and productivity of all people".

"I really don't think we are deceiving people," says Robinson. "I have published in the past in PNAS and I chose the format because I liked it. I wanted the format that scientists are used to reading." Robinson says the paper is now being submitted to an undisclosed journal for publication.

Colin Macilwain

\section{Teachers gain aid for evolutionary struggle}

[WASHINGTON] The National Academy of Sciences, alarmed by what it says is continuing hostility to the teaching of evolution in many school districts in the United States, has produced a glossy guide to advise teachers on how the subject can be best taught.

The guide is designed to help teachers in parts of the country, primarily in the south, where Christian groups have tried to ensure that 'creation science' is taught alongside evolution. It says that the Supreme Court rejected that idea in 1987, when it held that a Louisiana decree calling for the "balanced treatment" of the two was unconstitutional.

"We're not saying that teachers can flaunt their state rules," says Maxine Singer, president of the Carnegie Institution of Washington and one of the guide's authors. "But they could challenge them legally" on the basis of the Supreme Court ruling, she says.

The guide says that the emergence of genetics has made the theory of evolution a central tenet of biology, which teachers can-

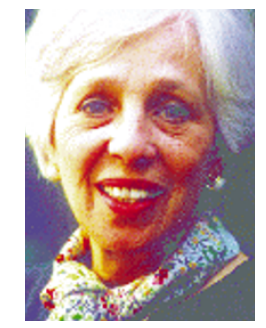

Singer: option of legal challenge. not choose to ignore. enly assume that evolution has little to do with science as it is practised today, says Singer. "A few years ago, evolution was not of major interest to molecular biologists," she says. "But now it is." that require the teaching of creationism. Schools are usually administered, however, by counties and problems arise in all regions of the United States.

Donald Kennedy of Stanford University, who chaired the group of 13 authors, declines to estimate how many teachers are intimidated by such policies.

"If you listen to enough teachers you become persuaded that this is a serious problem," Kennedy says.

C.M. Many teachers mistak- 